\title{
Structure of periadrenal brown fat in childhood in both expected and cot deaths
}

\author{
JOHN L. EMERY AND FAY DINSDALE \\ From the Department of Pathology, Children's Hospital, Sheffield
}

SUMmARY A quantitative study was carried out of the fat cells of the hilar pannicle of the adrenal in 150 infants comprising 60 hospital deaths, 2 accidental deaths, and 88 cot deaths. The cells were rated in categories of fat vacuolation. For a period of up to 8 weeks after birth there is an apparent depletion in the number and size of overt fat vacuoles in the cell and from this time on there is a progressive change to monolocular fat cells. The postnatal discharge of fat from the cell in the pannicle seems to be reduced in some children presenting as unexpected death in infancy.

The past few years have been marked by a realisation that fat pannicles, particularly those associated with the viscera, are important metabolic organs in the infant (Hull, 1966; Hull and Hardman, 1970). Brown fat pannicles are distinguished by the possession of small fat cells having large mitochondria and a large proportion of cytoplasm to fat globules. Characteristically the cells contain many small fat globules as distinguished from the single large globule of the common white fat cell (Hull and Segall, 1966). As the brown fat cells become less active they become larger and look more and more like white fat cells. The so-called brown fat depots have been clearly linked to temperature regulation in the newborn child, but in addition recent evidence suggests that the structure of a fat pannicle is related to life at high altitudes and degrees of hypoxia (Dávila Meza and Sanchez Lihón, 1971; Teplitz and Lim, 1974). It has also been suggested (Naeye, 1974a, b) that children dying in what is described as the 'sudden infant death syndrome' show a retention of brown fat cells.

For many years we have been impressed by the extreme variability of the general histological appearance of visceral fat pannicles in infants of the same age, and it was thought worthwhile to attempt a quantitative histological assessment of a specific visceral fat pannicle in infants, and to relate the findings to the type of death. While general areas of fat are easily identifiable, the selection of a particular site for study is not easy. Adjacent fat pannicles, particularly in the neck and even around the adrenal, frequently show quite different gross cell appearances.

The pannicle we decided to use is that which is enclosed between the leaves of the adrenal at its Received 30 June 1977 hilum. At this point there is a consistent mass of fat bounded on two sides by adrenal cortex, easily identifiable and obtainable at necropsy.

\section{Material and methods}

Adrenals from a sequential series of 150 children coming to necropsy at the Children's Hospital, Sheffield, were used. They included 6 stillborns, 95 children between birth and 6 months of age, 24 between 6 months and a year, and 25 between the ages of 1 and 16 years. Of these, 60 were hospital deaths, 2 known accidental deaths, and 88 presented as unexpected deaths in infancy. All of the latter cases were divided into degrees of explanation of deaths as previously described (Protestos et al., 1973) in order to subdivide the partly explained from the unexplained unexpected deaths. Of these 88 children, 37 came into the $\mathrm{A}$ and $\mathrm{B}$, i.e. explained group, and 50 into the $C$ and $D$ groups where death is relatively unexplained.

The fat pannicle studied was situated between the leaves of the adrenal at the hilum of the gland. Left and right glands were used randomly. All the sections were examined without knowledge of the age of the child or the cause of death, and it was only after the fat cells in the pannicle had been graded that any correlation was made.

The fat cells were divided into seven categories, based on the following histological criteria (Fig. 1). (1) Cells having uniform granulation with no vacuoles and the nucleus usually central. (2) Cells with almost uniform granular cytoplasm containing a few small vacuoles and central nucleus. (3) The granular cytoplasm contained definite 
vacuoles but the vacuoles occupied less than half of the area of the cell cytoplasm. Again the nucleus is usually central. (4) The granular cytoplasm contains many vacuoles occupying more than half of the cell cytoplasm, the vacuoles are larger but the nucleus still lies within the body of the cell. (5) The granular cytoplasm contains one or two large vacuoles and the nucleus is now applied to the cell wall. (6) The cell is now largely occupied by a single large vacuole but a distinct edge of granular cytoplasm often blurred on the inner aspect is visible around the cell wall, the nucleus being applied to the cell wall. (7) A typical adult type cell with a single vacuole and apparently flattened peripheral nucleus and cytoplasm being almost absent, as seen in ordinary microscopy. Photographs and diagrams were available for constant reference by the person assessing the fat pannicle.

The pannicles were assessed using a Swift Point Counter and a square central graticule. The pannicle was surveyed stepwise under high power and the number and type of cells within the graticule square counted. Cells in contact with the right and inferior wall were discarded as in routine blood counting technique, and those cutting the left and superior wall included. The nucleus was not necessarily visualised in every cell counted. The pannicle was surveyed until a total of 500 fat cells had been counted. This gave a differential count of the types of fat cells present. Reproducibility trials showed that in a series of 20 random cases there was no disagreement in the maximal number of fat cells being placed in any one category and this was achieved on a 500 cell count.

\section{Results}

The cell morphology profiles were worked out for each child. These show irregular patterns within all age groups, making generalisation extremely difficult. This is illustrated by Fig. 3, which shows the proportion of apparently mature cells (type 7) in the pannicle. In a small number of children dying at birth the pannicles contain up to $15 \%$ of this type of cell and in several children dying from the age of 9 weeks onward over half of the cells appear to be of type 7. It is only after the age of approximately 25 weeks that this type of cell was seen in every pannicle assessed.

In order to give the pattern of cell type mathematical expression, a scoring method was devised that would give an indication of the predominant cell picture and thus the possible degree of metabolic activity. The cells of type 7 were rated 1 , because they appeared to us to be the least active metabolically; those of type 5 and 6 given a numerical value of 2 ; cells of type 3 and 4 a value of 3 ; and cells of type 1

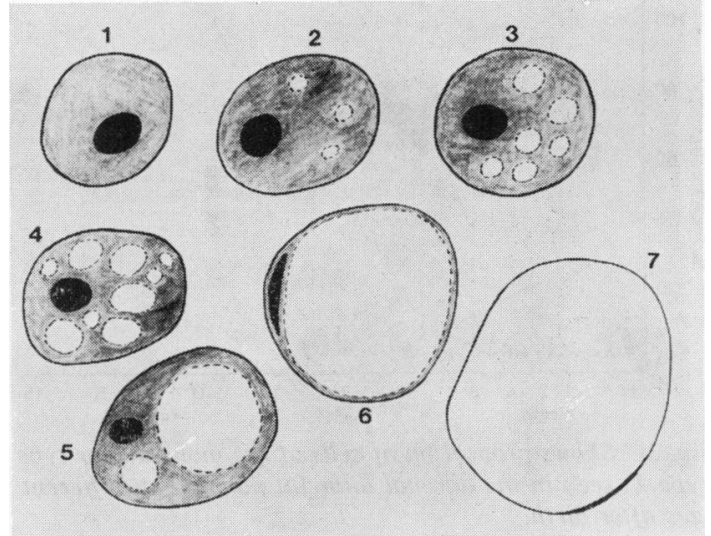

Fig. 1 Shows the classification of cell types. For description see text.

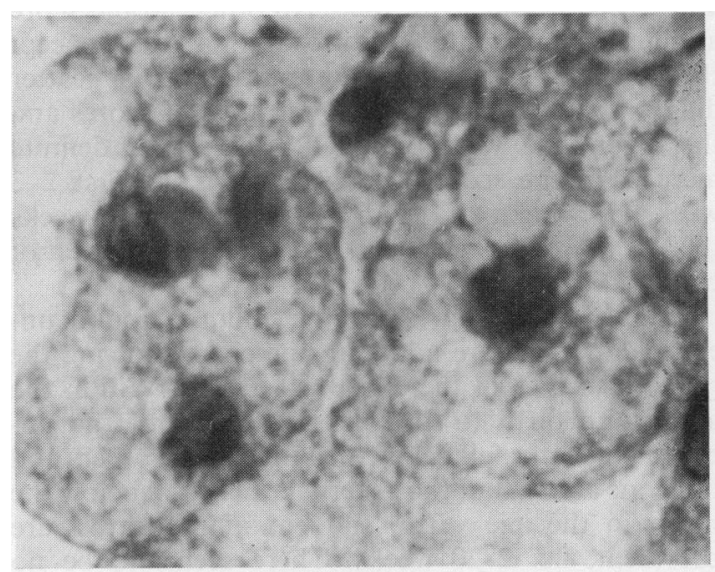

(a)

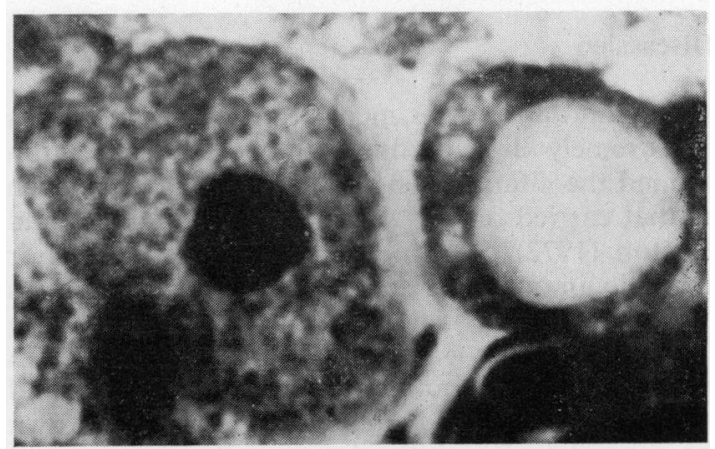

(b)

Fig. 2 Photographs of fat cells sinowing, from left to right, cells of (a) types 2 and $4,(b) 1$ and 5. 


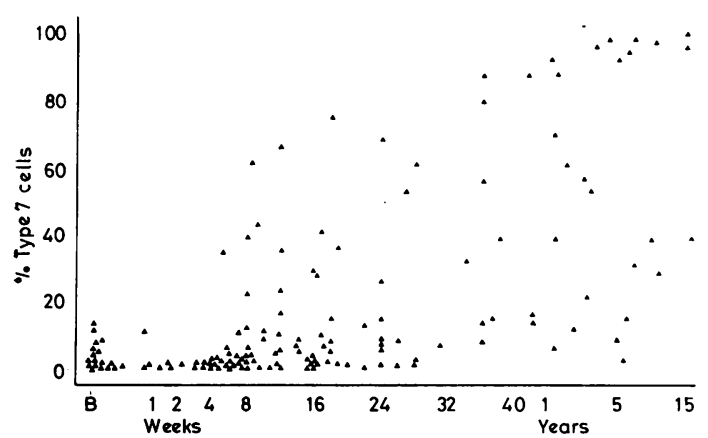

Fig. 3 Shows proportion of cells of the monolocular type (type 7) seen in the adrenal hilar fat pannicle at different ages after birth.

and 2 a value of 4 . In each case 500 cells were counted and thus a pannicle showing all cells of type 7 would score 500, those containing all type 1 and 2 cells would score 2000 . All others would score an intermediary grade. The scores for all cases except the unexpected deaths were plotted as a scatter diagram and from this the total range of scores and the mean line were obtained (Fig. 4). A definite increase in the score occurred during the first 2-3 weeks after birth and from the age of about 6 weeks there is a progressive decrease throughout the rest of childhood.

In Fig. 5 the scores for the children found unexpectedly dead are added to the chart showing the range of scores in the explained deaths. Within the age group birth to 36 weeks, 29 cases of the unexpected deaths fell below the range of the others and only one above, but the general level is well below the mean in the age when 'sudden infant deaths' are prevalent, i.e. 2-20 weeks. There seems to be no obvious difference in distribution between the various categories of unexpected deaths.

\section{Discussion}

Any quantitative assessment of brown fat in infants is extremely difficult due to its wide distribution around the infant. Even studies of distribution such as that carried out by Aherne and Hull (1966) and Heaton (1972) give only a crude assessment. For example, in our experience the most consistent mass of brown adipose tissue lies round the spinal cord in the lumbar region-a mass which is not indicated in the latter survey. Routine sections from the neck and other parts of the body in children also show brown fat pannicles of multilocular fat cells interdigitated with pannicles of unilocular cell type, and it appears to be completely impracticable to make a whole body assessment.

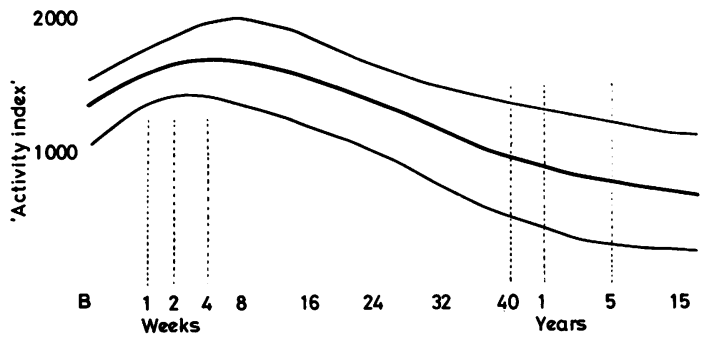

Fig. 4 Distribution curve including the mean, 0 , and 100 th centile of the histological profile of the fat cells in the adrenal hilar fat pannicle related to postnatal age in all hospital and other deaths but excluding those dying unexpectedly at home. An expanded scale is used up to the age of 40 weeks.

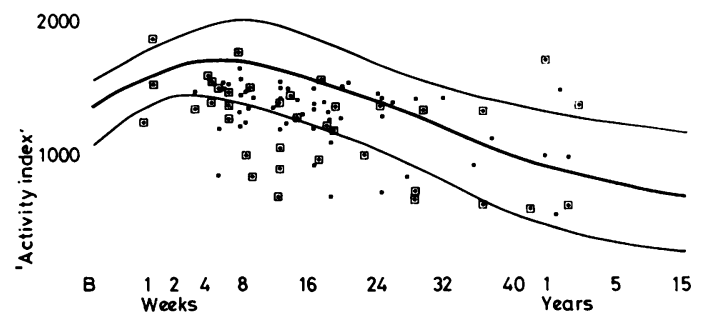

Fig. 5 Fat cell scores of the children presenting as unexpected deaths compared with the rest of child deaths. The unexplained, unexpected sudden deaths $(C$ and $D)$ are shown as solid squares and the explained sudden deaths $(B)$ are enclosed in squares.

The persistence of multilocular fat seems to vary greatly from site to site; for example in the interscapular area and greater omentum brown fat is present in infancy and childhood but absent in old people, whereas the multilocular fat persists until old age in sites associated with the neck and intercostal vessels (Heaton, 1972). The pannicle we have studied lies in the centre of the area which all observers accept as sites of brown fat, and is probably the most easily identifiable mass of fat in the body.

Assessment of brown adipose tissue round the adrenal, such as that recorded by Naeye (1974a, b), seems to us to be highly subjective, depending on how much tissue was removed. The simple division of fat into brown and non-brown is extremely subjective. Naeye's division of cells does not depend on whether the cells are uni- or multilocular but on the presence or absence of a reticular cytoplasm. What degree and amount of multilocular fat in a pannicle makes the pannicle 'brown' or 'white' is uncertain, and for this reason we divided our cells into cell types which are reasonably reproducible. The mathematical grading of the cells is arbitrary. 
The method which we have used in this study is confined to a single pannicle and thus can only be interpreted for that pannicle. We have not as yet made parallel studies of other pannicles for two reasons; it is difficult to find another equally welldefined pannicle to study, and we have at the moment no idea as to which could be the most significant pannicle. However, the general appearance of the adrenal fat pannicle is usually similar to pannicles in such sites as the mesentery and portal area.

Aherne and Hull (1966), in a survey of sections from 187 babies, stated that morphologically the fat content of the brown fat fell over the first 4 days after birth, and that in many babies dying after the 8th day the brown fat cells were either partially or totally depleted of fat. Our findings appear to both confirm and extend their observations, but also show that the period of depletion takes place over a longer period, i.e. up to 8 weeks after birth.

To relate histological appearance to metabolic activity may be taking an unjustifiable step. The discharge of fat from brown fat pannicles may indicate a heightened activity or partial exhaustion and we are not convinced that we can make a direct correlation between histological appearance and the interpretation of fat pannicles. The scoring method we have used is essentially a method which quantitates the number of fat cells within the brown fat pannicle having a smaller and reduced number of overt fat globules, and we would be going beyond our evidence to suggest the implication of this at the present time.

A postnatal depletion in large fat globules in the adrenal brown fat in children dying in the perinatal period up to 8 weeks after birth may indicate a disease factor or a physiological one. The pattern is so consistent in children dying from such a variety of conditions that the physiological factor seems most justifiable.

The situation regarding children found unexpectedly dead poses a problem. Until a few years ago it was common practice to regard these babies as virtually normal controls as they were thought to show little evidence of overt pathological processes. We have shown elsewhere (Sinclair-Smith et al., 1976) that these children on a nonspecific basis show at least equal evidence of having responded to general disease, as do hospital deaths, and thus we can no longer use arguments on degrees of normality. All we can say at the moment is that some of the group of children who are found unexpectedly dead appear superficially to have responded, from a specific brown fat pannicle point of view, differently from those who died in hospital from known disease. It is not possible to relate our observations regarding the aetiology of 'sudden infant deaths' directly to the observations of Naeye. In his 1974a paper he notes that his method of studying brown fat is of little value under the age of 3 months. In his 1976 paper (Naeye et al.) he excluded from his analysis of fat all children under the age of 5 months, and therefore excludes most cot deaths.

In the cases of unexpected death which we have studied which were older than 5 months the rating of the fat pannicle falls within the same range as the 'controls'. In the children dying at a younger age, where the majority of the unexpected deaths occur in our material, the scores show an activity index lower than that of the 'controls'-fewer multilocular cells were counted. This is exactly the reverse of Naeye's suggestion based on his older children. It must be pointed out, however, that we believe that unexpected deaths are not due to a single condition but to a number of heterogeneous situations; even within the age group 2-30 weeks; in our material more than half the cases of unexpected death showed values within the same range as those found in children dying in hospital. We have not measured the total number of fat cells in the pannicle and are in no position to talk of hyperplasia or atrophy; we are simply concerned with the cytoplasmic state of the cells in the pannicle. The situation, however, calls for further study.

This study was supported by the Foundation for the Study of Infant Deaths.

\section{References}

Aherne, W., and Hull, D. (1966). Brown adipose tissue and heat production in the newborn infant. Journal of Pathology and Bacteriology, 91, 223-234.

Dávila Meza, M., and Sanchez Lihón, J. (1971). Comportamiento de la grasa parda a nivel del mar y en la altura. Archivos del Instituto de Biologia Andina, 4, 87-93.

Heaton, J. M. (1972). The distribution of brown adipose tissue in the human. Journal of Anatomy, 112, 35-39.

Hull, D. (1966). The structure and function of brown adipose tissue. British Medical Bulletin, 22, 92-96.

Hull, D., and Hardman, M. (1970). Brown adipose tissue in newborn mammals. Brown Adipose Tissue, Chap. 4, pp. 97-115. Ed. by O. Lindberg. Elsevier, New York.

Hull, D., and Segall, M. M. (1966). Distinction of brown from white adipose tissue. Nature, 212, 469-472.

Naeye, R. L. (1974a). SIDS-evidences of antecedent chronic hypoxia and hypoxemia. SIDS 1974. Proceedings of the Francis E. Camps International Symposium on Sudden and Unexpected Deaths in Infancy, pp. 1-6. Ed. by R. R. Robinson. Canadian Foundation for the Study of Infant Deaths, Toronto.

Naeye, R. L. (1974b). Hypoxemia and the sudden infant death syndrome, 1974. Science, 186, 837-838.

Naeye, R. L., Whalen, P., Ryser, M., and Fisher, R. (1976). Cardiac and other abnormalities in the sudden infant death syndrome, 1976. American Journal of Pathology, 82, 1-8. 
Protestos, C. D., Carpenter, R. G., McWeeny, P. M., and Emery, J. L. (1973). Obstetric and perinatal histories of children who died unexpectedly (cot death). Archives of Disease in Childhood, 48, 835-841.

Sinclair-Smith, C., Dinsdale, F., and Emery, J. L. (1976). Evidence of duration and type of illness in children found unexpectedly dead. Archives of Disease in Childhood, 51, 424-429.
Teplitz, C., and Lim, Y. C. (1974). The diagnostic significance of diffuse brown adipose tissue (B.A.T.). Transformation of adult periadrenal fat: a morphologic indicator of severe chronic hypoxemia. Laboratory Investigation, 30, 390.

Correspondence to Professor J. L. Emery, Children's Hospital, Western Bank, Sheffield S10 2TH.

The following articles will appear in future issues of this journal:

Annotation. Faecal soiling and anal achalasia. J. F. R. Bentley.

Review article. The first feed of low birthweight infants: changing attitudes in the twentieth century. D. P. Davies.

Homocystinuria in New South Wales. Bridget Wilcken and Gillian Turner.

Renal scarring and vesicoureteric reflux. K. J. Shah, D. G. Robins, and R. H. R. White.

Tracheal compression as a cause of respiratory symptoms after repair of oesophageal atresia. $R$. $C$. $M$. Cook and G. H. Bush.

Reflex anoxic seizures ('white breath-holding'): nonepileptic vagal attacks. J. B. P. Stephenson.

Familial haemolytic uraemic syndrome. A. D. Edelsten and S. Tuck.

Congenital heart block and hypothyroidism. A. A. Syed. 